\title{
Sacroiliitis and HLA. A clinical and genetical study
}

\author{
N. MIGONE, ${ }^{*}$ V. MODENA, $\dagger$ V. DANEO, $\uparrow$ \\ A. O. CARBONARA,* AND R. CEPPELLINI +
}

SUmmaRY Among 39 patients (23 males, 16 females) with sacroiliitis (SI) 17 were HLA-B27 positive. The female/male ratio in the B27-positive group was $2 / 15$. Seventy-four first-degree relatives of 26 probands were also investigated. A high occurrence of SI $(20 \%)$ was observed in the families of B27-positive probands compared with only $3.7 \%$ in the families of B27-negative probands. In the former families SI occurred only in B27-positive subjects with an earlier onset of symptoms and a male prevalence. In the latter, the disease showed a later onset and a lack of male preponderance. The nosological and prognostic relevance of the B27 typing is stressed.

The inflammatory involvement of sacroiliac joints is one of the first and constant signs of classical ankylosing spondylitis (AS). This strong association has been so widely confirmed that the presence of sacroiliitis (SI) is an essential requirement for AS diagnosis according to the 'New York criteria' (Gofton, 1968). It is also well known that SI may be found in patients without any further tendency to spinal involvement.

The nosological distinction between AS and SI is not well established. However, some epidemiological and clinical findings show that the two diseases display in part different behaviours: (a) the prevalence of SI in the population is estimated by the majority of authors to be about one order of magnitude higher than that of AS (1-3\% versus $0.2 \%$; but see Kidd et al., 1977); (b) the sex ratio does not show the established higher proportion of males found among AS probands; (c) the association with the HLA-B27 antigen differs in the two diseases, being about $90 \%$ in AS and significantly lower in SI.

Family studies carried out on AS together with HLA typing have already shown the high familiality and the major role played by the B27 antigen in the susceptibility to the disease: about $22 \%$ of the firstdegree relatives were affected, all of them carried the B27 antigen. On the basis of these results it was concluded that susceptibility to AS is controlled by a

Accepted for publication February 15, 1978

This work was supported in part by CNR, Centro di Studio per l'Immunogenetica e l'Istocompatibilità, Torino.

* Istituto di Genetica Medica dell 'Università, Torino, Italy, † Centro di Reumatologia, Ospedale S. Giovanni Battista. Torino, It ly.

¥ Basel Institute of Immunology, Basel, Switzerland. major gene, dominant and linked to HLA with a penetrance of about 30-40\% (Contu et al., 1977; Daneo et al., 1977; Kidd et al., 1977).

Following the same approach it was decided to carry out a family study on SI. The results show that it is possible to recognise among SI patients two distinct clinical entities with different genetic and prognostic patterns.

\section{Patients and methods}

\section{Patients}

Thirty-nine probands (or primary cases) were selected among those patients who had been attending the Rheumatological Centre (San Giovanni Hospital, Torino) during the last 10 years, and who had been diagnosed as having SI. In order to obtain a more homogeneous sample, those patients showing associated diseases (psoriasis, ulcerative colitis, Crohn's disease, and Reiter's syndrome) were excluded. A total of 74 first-degree relatives of the probands were examined. All probands and their relatives (over the age of 15 years) were HLA typed and submitted to careful pelvic $x$-ray examination. Furthermore, they were investigated for signs and symptoms related to the axial and peripheral muscolo-skeletal system. Cardiovascular, respiratory, gastrointestinal, skin, and neurological functions were also checked.

To assess the SI prevalence in our 'normal' population from an unbiased sample, 213 pelvic $x$-ray films of patients with urological complaints were chosen at random from the records of the Department of Urology and examined for SI with the same criteria as given below. Pathological signs of SI were found in $1.87 \%$ of the subjects 
with no significant sex difference $(2 / 101$ males; $2 / 112$ females).

\section{DIAGNOSTIC CRITERIA}

In probands and in relatives a diagnosis of SI was established when the two following conditions were fulfilled.

(1) Definite radiological involvement of the sacroiliac joints, either at one or both sides, according to Gofton (1968): $0=$ normal; $1=$ doubtful; $2=$ unequivocal sacroiliitis, characterised mostly by marginal sclerosis with minimal erosions without clear alteration of the joint width; $3=$ preponderance of erosions, widening, and narrowing of the oint width with partial ankylosis; $4=$ total ankylosis. The scores were assigned blindly and independently by a rheumatologist and a radiologist. In the case of discordance the lower score was assigned. A definite diagnosis of SI was made in the presence of a score of 2 or more, at one or both sides. Individuals showing doubtful signs were considered to be normal.

(2) Absence of signs and symptoms that should justify a diagnosis of AS, either probable or definite, according to the so called 'New York criteria' (Gofton, 1968).

\section{HLA TYPING}

Probands and relatives, of a total of 113 individuals, were typed by the standard NIH lymphocytotoxicity technique (Ray et al., 1976) for the following HLA-A, B, and C locus specificities: A1, 2, 3, 9 (w23, w24), $10(25,26), 11,28$, w19 (29, w30, w31, w32, w33); B5 (w51, w52, w53), 7, 8, 12 (w44, w45), 13, 14, 15 (To52, To53), 17, 18, w21 (w49, w50), w22, 27, w35, w37, w16 (w38, w39), 40, w47; Cw1, w2, w3, w4, w5.

A previous study had shown that HLA-D polymorphism and, by implication, DR antigens did not add any relevant information (Truog et al., 1975).

A panel of 1428 normal individuals, from the Italian population, typed for HLA was the control for antigen frequencies.

\section{Results}

\section{PROBANDS}

A total of 39 probands was studied. The sex distribution, 23 males $(59 \%)$ and 16 females $(41 \%)$ did not differ significantly. The mean ages of the two groups were comparable (39 years in males versus 41 in females), the total age range being 15 to 66 years with a mean of $40 \pm 14 \cdot 66$ (Table 1). From the clinical point of view, 9 out of 39 probands showed monolateral SI. The other 30 showed bilateral SI.
Table 1 Age and sex distribution of $H L A-B 27$ positive and negative SI probands

\begin{tabular}{|c|c|c|c|c|c|}
\hline \multirow[t]{2}{*}{$B 27$} & \multirow[t]{2}{*}{ Total (\%) } & \multicolumn{2}{|c|}{ Sex } & \multirow[t]{2}{*}{ Age range (years) } & \multirow{2}{*}{$($ mean $\pm S D) \stackrel{\text { ? }}{\text { (?) }}$} \\
\hline & & $F$ & $M$ & & \\
\hline \pm & $\begin{array}{l}17(43 \cdot 6) \\
22(56 \cdot 4)\end{array}$ & $\begin{array}{r}2 \\
14\end{array}$ & $\begin{array}{r}15 \\
8\end{array}$ & $\begin{array}{l}15-57 \\
15-66\end{array}$ & $\begin{array}{l}37 \cdot 5 \pm 13 \cdot 49 \\
42 \cdot 7 \pm 15 \cdot 42\end{array}$ \\
\hline Total & $39(100)$ & 16 & 23 & $15-66$ & $40 \cdot 4 \pm 1$ \\
\hline
\end{tabular}

The distribution of the mono and bilateral in $\overrightarrow{5}$ volvement did not differ significantly between the two sexes $(P=0 \cdot 26)$.

Seventeen cases $(43.6 \%)$ were positive for antige HLA-B27, indicating a highly significant associatioñ when compared to a frequency of $4.3 \%$ among controls $\left(\chi^{2}=108 \cdot 9\right)$. The relative risk, according tos Woolf's formula (1955), was $17 \cdot 3$. No significarte deviation was observed for any other HLA specificity.

When the HLA typing was taken into account the following observations emerged: (a) the B27=positive probands were in the majority males $(88 \%$ $15 / 23$ males, versus $2 / 16$ females: $P<\cdot 01$ ); (b) the onset of the first osteoarticular complaint arose at af earlier age in the B27-positive individuals. This particularly evident for talalgia $\left(t_{6}=3 \cdot 70 ; P \simeq 0 \cdot 01\right)_{6}$ (c) the severity of SI involvement, expressed accardo ing to bilateral versus monolateral involvement, significantly greater among B27-positive patiẹpos $(\mathrm{P}=0.028)$ (Table 2).

\section{RELATIVES}

Seventy-four first-degree relatives of 26 primar cases were examined (14 parents, 24 children, $3 \frac{6}{6}$ sibs; 43 males, 31 females). They were divided int two groups, according to the presence or absence of the B27 antigen in the proband. The prevalence of SI in the two groups is shown in Table 3.

\section{Group 1}

Among 20 relatives of 9 B27-positive probands, individuals had clear radiological signs of SI $(20 \%$ One of them (a father) was affected by a bilateral ST at an advanced stage and by typical dorsolumbar syndesmophytosis (thus suggesting AS); 1 other (o brother) had definite bilateral SI; the other 2 ( mother and a sister, both in the same family) pres sented a definite monolateral SI. The HLA typing

Table 2 Radiological SI involvement and HLA-B27 in probands

\begin{tabular}{|c|c|c|c|}
\hline$B 27$ & Total & Monolateral SI & Bilateral \\
\hline+ & $\begin{array}{l}17 \\
22\end{array}$ & $\begin{array}{l}1 \\
8\end{array}$ & $\begin{array}{l}16 \\
14 \\
\end{array}$ \\
\hline \multicolumn{4}{|c|}{$\mathbf{P}=0.0279$ (Fisher's exact test) } \\
\hline
\end{tabular}


Table 3 Occurrence of SI

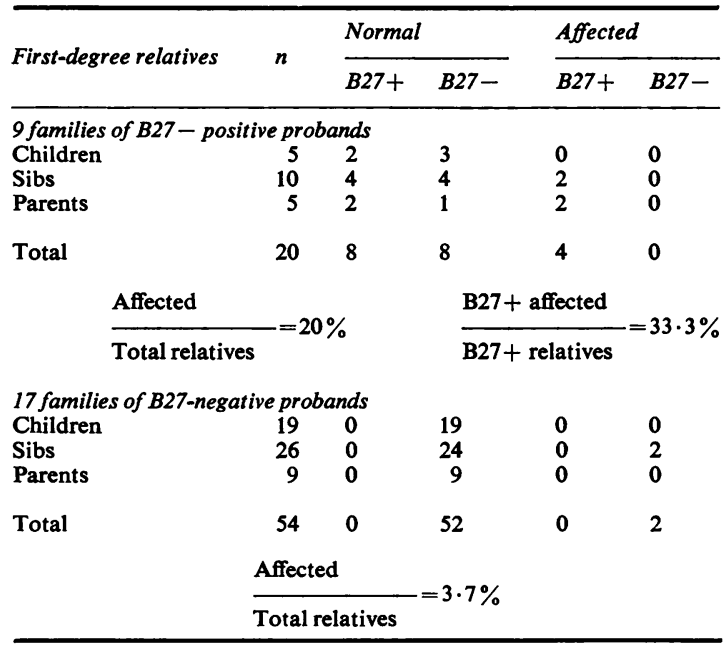

showed that all the 4 relatives, for whom a diagnosis of SI was justified, carried the B27 antigen. Thus, the ratio of those affected individuals to the total of the B27-positive relatives (4/12) is $33 \%$.

\section{Group 2}

Among 54 relatives of $17 \mathrm{~B} 27$-negative probands, only 2 cases were found to be affected by definite monolateral SI. They were two male sibs (belonging to different families) both B27-negative. Thus in this group the frequency of SI is only $3.7 \%$, lower than that found among relatives of $\mathrm{B} 27$ positive probands $(P=0.084$ is, however, of marginal significance).

\section{Discussion}

Primary radiological involvement of the sacroiliac joints has been recognised to occur at a variable rate in different populations (Gofton et al., 1966; 1972). The epidemiological data available, based mainly on random samples of pelvic $x$-ray films, always show higher rates of SI in comparison to AS (Table 4). According to the country investigated, the SI prevalence exceeds by 2 to 10 times that of ankylosing spondylitis.

A common aetiopathogenetic mechanism for the two diseases has been suggested by the constant findings of high SI rates among populations with high AS prevalence. The well documented association of both AS and SI with the HLA-B27 antigen (Brewerton and Albert, 1977) is additional evidence of the relationship between the two diseases. On the other hand, the degree of the association with the B27 antigen is clearly different in the two cases: constantly higher for AS, significantly lower for sacroiliitis.

In the majority of HLA studies there is no clear evidence that the authors did discriminate between SI and AS. Among the few exceptions Möller $e t$ al. (1975) reported a B27 positivity of $70 \%$ in a group of 60 SI patients from Scandinavia, while in the same study all AS patients were B27 positive. Our results in 39 SI probands give a B27 frequency of $43.6 \%$. The size of the samples, the genetic background, the environmental conditions, the assessment of diagnosis are all factors that may explain the observed difference.

In any case, the variability in the degree of association between B27 and SI, contrasts with the

Table 4 Prevalence of SI and AS in different populations, compared to the B27 frequency

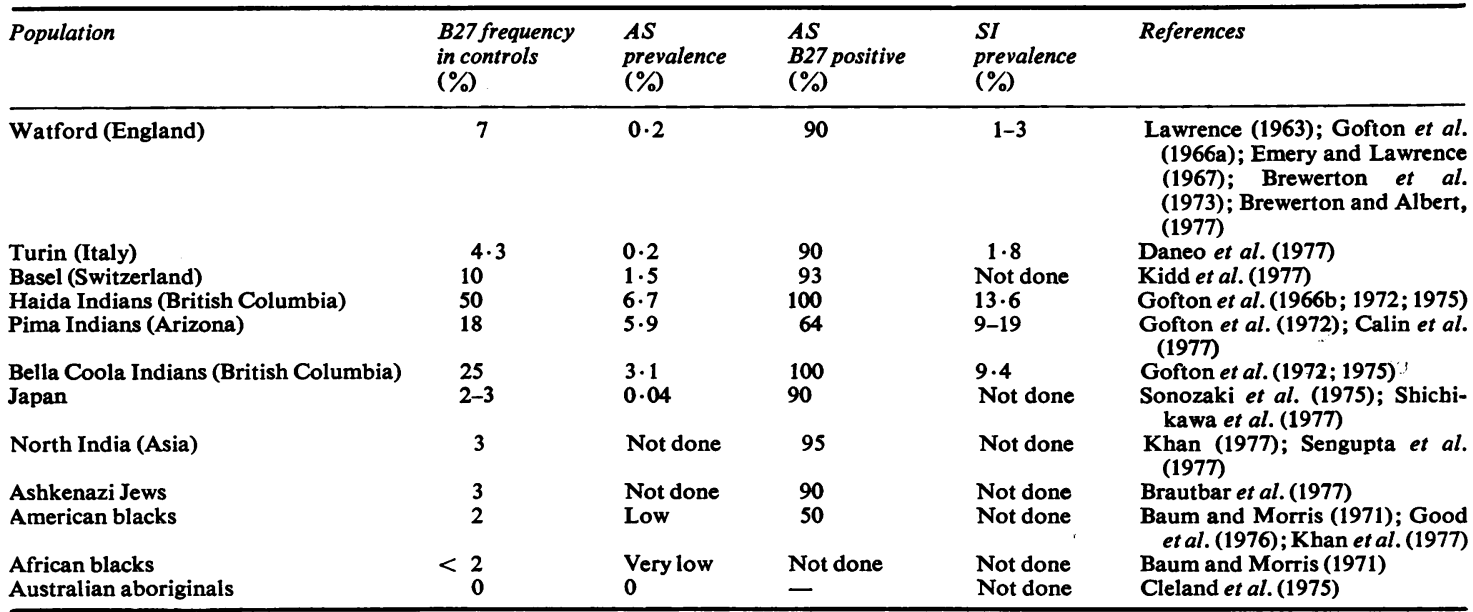


rather uniform results obtained for AS in all populations tested. This suggests that the so called SI represents a more heterogeneous clinical entity. This interpretation is also in agreement with our observations indicating several differences, at the clinical level, between B27-positive and B27negative SI patients. The main distinguishing features are the following.

\section{SEX}

Whereas the B27-positive probands display an evident male preponderance, the B27-negative ones show no significant difference between sexes (perhaps a slight female excess). Similar findings have been reported by Calin et al. (1977).

\section{AGE OF ONSET}

First symptoms of the disease together with other related rheumatic complaints seem to appear early in the B27-positive patients. Although in our data these differences are statistically significant only for talalgia, such a trend for the majority of symptoms is worthy of note.

\section{FAMILIALITY}

A greater number of SI individuals were found among relatives of B27-positive probands $(20 \%$ versus $3.7 \%$ among the relatives of $\mathrm{B} 27$-negative probands). Moreover in the former group the secondary cases seem to be more severely affected than in the latter.

In spite of the lack of statistical significance for most of the differences reported, it is none the less justified the attempt of splitting sacroiliitis into two distinct nosological entities. One, recognised through the presence of the B27 marker, shows family data very similar to those reported by our group for AS (Daneo et al., 1977; Kidd et al., 1977). In both diseases the frequency of secondary cases among first-degree relatives is high and confined to carriers of the B27 chromosome. Moreover, the ratio of B27 affected individuals to total B27 relatives, which allows an estimate of the penetrance of the 'illness susceptibility' gene, is very similar: $33 \%$ versus approximately $35 \%$.

The similarities between B27-positive SI and AS cases allow the suggestion that they represent different levels of expression or different stages of the same genetic pathological entity. Thus in B27 individuals the SI can be regarded as a first step towards the likely (but not certain) development of clearcut AS. It is known, in fact, that involvement of the sacroiliac joints is one of the first signs to appear in AS patients, before spinal symptoms or signs. Often the disease found in relatives of AS patients has the features of SI, which will only in some cases reach the involvement of the spine. Onthe other hand, it is interesting that among affected? relatives of SI probands in this study at least one shows, besides SI, typical syndesmophytosis as in? classical ankylosing spondylitis.

In conclusion, for this variant of SI, which coulde be regarded as a latent form of AS, the B27 marke plays the same role, as indicator of the 'illness gene'? as in ankylosing spondylitis.

The other group of SI patients, recognised by being B27-negative, covers a large proportion (morèthan $50 \%$ in this study) of the total cases affectedw by sacroiliitis. Apart from the absence of B27, the nolosogical distinction of this group is outlined byo an equal incidence and severity in the two sexes, w less severe involvement of sacroiliac joints, and क् low familiality. In fact the frequency among first degree relatives $(2 / 54)$ is close to the reported prevalence in the general population $\left(4 / 213 ; \chi^{2}=\right.$ 0.086 ). Within their limitations in size and type, the data reported here do not allow us to accept for B27-negative SI the genetic model of a single majok locus with incomplete penetrance, as has beer proposed for AS though it is likely valid also fo@ the B27-positive variant of SI. As a matter of fact these data do not even support a significant rolegofo the genotype for the appearance of SI in a B\&7:negative subject.

The relative role of a major locus versus a multis

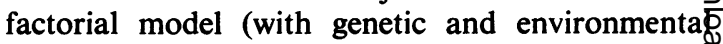
components) in the aetiology of SI and AS can also be tentatively interpreted from the frequency of B27 antigen among SI and AS patients which ofters accompany a rather heterogeneous group of $s \odot$ called 'rheumatoid variants' (Crohn's disease ulcerative colitis, Reiter's syndrome, and psoriatic. arthritis).

According to the majority of published data, the frequency of B27 in AS 'complicating' Crohn'通. disease and ulcerative colitis is significantly highein than in normal controls but significantly lowes $(60 \%)$ than in patients affected by typical uncom ${ }_{-}$ plicated AS (Russell, 1977). By contrast SI, whicl? accompanies the above syndromes in about $15 \%$ of cases (Wright and Watkinson, 1965), shows a levef of the B27 marker of about $20-30 \%$, ie, not siger nificantly lower than the level observed by us for uncomplicated SI. This suggests that the threshold of liability for AS is lowered by the agents responsible for the accompanying disease which can partially substitute and/or dilute the effect of the majof B27-associated gene. The same agents also increase the liability for SI $(15 \%$ versus $1.5 \%$ in the general population), again suggesting a partially common aetiology between the two diseases. 
In conclusion, our observations confirm the usefulness of having a genetic marker associated with a disease not showing a Mendelian pattern of inheritance. In the case of sacroiliitis the relevance of the B27 antigen lies not only in the nosological but mainly in its prognostic implications. In such an hetergeneous disease the HLA-B27 typing may help to distinguish those patients at risk for a probable later evolution towards full expression of typical ankylosing spondylitis.

The excellent technical assistance of Miss Clara Finà, Mrs Maura Cornaglia, and $\mathrm{Mr}$ Donato Marsico is acknowledged.

\section{References}

Baum, J., and Morris, Z. (1971). The rarity of ankylosing spondylitis in the Black Race. Arthritis and Rheumatism, 14, 12-18.

Brautbar, C., Porat, S., Nelken, D., Gabriel, K. R., and Cohen, T. (1977). HLA B27 and ankylosing spondylitis in the Israeli population. Journal of Rheumatology, 4 (Suppl. No. 3), 24-32.

Brewerton, D. A., and Albert, E. (1977). Rheumatologyankylosing spondylitis. In $H L A$ and Disease, pp. 94-95, ed. by J. Dausset and A. Svejgaard. Munksgaard: Copenhagen.

Brewerton, D. A., Hart, F. D., Nicholls, A., Caffrey, M., James, D. C. O. and Sturrock, R. D. (1973). Ankylosing spondylitis and HL-A27. Lancet, 1, 904-907.

Calin, A., Bennett, P. H., Jupiter, J., and Terasaki, P. I. (1977). HLA-B27 and sacroiliitis in Pima IndiansAssociation in males only. Journal of Rheumatology, 4 (Suppl. No. 3), 44-48.

Cleland, L. G., Hay, J. A. R., Milazzo, S. C. (1975). Absence of HL-A 27 and of ankylosing spondylitis in Central Australian Aboriginals. (Abstract.) Scandinavian Journal of Rheumatology, 4, (Suppl. No. 8), 30-05.

Contu, L., Capelli, P., and Sale, S. (1977). HLA B27 and ankylosing spondylitis: a population and family study in Sardinia. Journal of Rheumatology, 4 (Suppl. No. 3), 18-23.

Daneo, V., Migone, N., Modena, V., Bianchi, S. D., Alfieri G., Diotallevi, P., Carbonara, A. O., and Piazza, A. (1977), Family studies and HLA typing in ankylosing spondylitis and sacroiliitis. Journal of Rheumatology, 4 (Suppl. No. 3), 5-10.

Emery, A. E. H., and Lawrence, J. S. (1967). Genetics of ankylosing spondylitis. Journal of Medical Genetics, 4, 239-244.

Gofton, J. P. (1968). Report from the subcommittee on diagnostic criteria for ankylosing spondylitis. In Population Studies of the Rheumatic Diseases, pp. 314-316, ed. by P. H. Bennett and P. H. N. Wood. (International Congress Series No. 148.) Excerpta Medica Foundation.
Gofton, J. P., Bennett, P. H., Smythe, H. A., and Decker, J. L. (1972). Sacroiliitis and ankylosing spondylitis in North American Indians. Annals of the Rheumatic Diseases, 31, 474-481.

Gofton, J. P., Chalmers, A., Price, G. E., and Reeve, C. E. (1975). HL-A 27 and ankylosing spondylitis in B.C. Indians. Journal of Rheumatology, 2, 314-318.

Gofton, J. P., Lawrence, J. S., Bennett, P. H., and Burch, T. A. (1966a). Sacroiliitis in eight populations. Annals of the Rheumatic Diseases, 25, 528-532.

Gofton, J. P., Robinson, H. S., and Trueman, G. E. (1966b). Ankylosing spondylitis in a Canadian Indian Population. Annals of the Rheumatic Diseases, 25, 525-527.

Good, A. E., Kawanishi, H., Schultz, J. S. (1976). HLA B27 in Blacks with ankylosing spondylitis or Reiter's disease. New England Journal of Medicine, 294, 166-167.

Khan, M. A., Braun, W. E., Kushner, I., Grecek, D. E., Muir, W. A., and Steinberg, A. G. (1977). HLA-B27 in ankylosing spondylitis: differences in frequency and relative risk in American Blacks and Caucasians. Journal of Rheumatology, 4 (Suppl. No. 3), 39-43.

Khan, M. A. (1977). Ankylosing spondylitis and HLA-B27 in Punjabis. The Lancet, 2, 504.

Kidd, K. K., Bernoco, D., Carbonara, A. O., Daneo, V., Steiger, U., and Ceppellini, R. (1977). Genetic analysis of HLA-associated diseases: the "illness susceptible" gene frequency and sex ratio in ankylosing spondylitis. In $H L A$ and Disease, pp. 72-80, ed. by J. Dausset and A. Svejgaard. Munksgaard: Copenhagen.

Lawrence, J. S. (1963). The prevalence of arthritis. British Journal of Clinical Practice, 17, 699-705.

Möller, E., Olhagen, B. (1975). Studies on the major histocompatibility system in patients with ankylosing spondylitis. Tissue Antigens, 6, 237-246.

Ray, J. G., Hare, D. B., Pedersen, P. D., and Mullaly, D. I. (Editors). (1976). N.I.A.I.D. Manual of Tissue Typing Techniques, pp. 22-28. DHEW Publication No. (NIH), 76-545.

Russell, A. S. (1977). Arthritis, inflammatory bowel disease, and histocompatibility antigens. Annals of Internal Medicine, 86, 820-821.

Sengupta, S., Sehgal, S., Aikat, B. K., Deodhar, S. D., and James, D. C. O. (1977). HLA B27 in ankylosing spondylitis in India. Lancet, 1, 1209-1210.

Shichikawa, K., Tsujimoto, M., and Nakata, S. (1977). Prevalence of ankylosing spondylitis in Japan. (Abstract.) In 14th International Congress of Rheumatology, San Francisco, June 26-July 1, 1977, p. 251.

Sonozaki, H., Seki, H., Chang, S., Okuyama, M., and Juji, T. (1975). Human lymphocyte antigen, HLA-27, in Japanese patients with ankylosing spondylitis. Tissue Antigens, 5, 131-136.

Truog, P., Steiger, U., Contu, L., Galfré, G., Trucco, M., Bernoco, D., Bernoco, M., Birgen, I., Dolivo, P., and Ceppellini, R. (1975). Ankylosing Spondylitis (AS): A population and family study using HL-A serology and MLR. In Histocompatibility Testing, pp. 788-796, ed. by F. Kissmeyer-Nielsen. Munksgaard: Copenhagen.

Woolf, B. (1955). On estimating the relation between blood groups and disease. Annals of Human Genetics, 19, 251-253.

Wright, V., Watkinson, G. (1965). Sacroiliitis and ulcerative colitis. British Medical Journal, 2, 675-680. 